\title{
\#QUÉESPOESÍA: GÉNERO Y NUEVAS POÉTICAS \\ PRODUCTIVAS EN LA ERA DE LAS REDES SOCIALES. \\ LAS POÉTICAS DE ELVIRA SASTRE, IRENE X Y LORETO SESMA
}

\author{
\#WHATISPOETRY: GENRE AND NEW PRODUCTIVE POETIC \\ WORK IN THE AGE OF THE SOCIAL NETWORKS. \\ THE POETRY OF ELVIRA SASTRE, \\ IRENE X AND LORETO SESMA
}

\section{Isabel LOGROÑO CARRASCOSA}

Universidad Isabel I

ilogronoc@gmail.com

Resumen: En los últimos años, redes sociales como Twitter, Instagram y Youtube se han convertido en populares plataformas de publicación y de difusión de contenidos literarios para jóvenes autores. Tanto es así que no son pocas las editoriales que han visto la oportunidad de convertir en cifras de ventas las cifras de seguidores, revitalizando incluso géneros minoritarios como la poesía. Sin embargo, ¿estamos verdaderamente ante una "revitalización" del género poético clásico o de una construcción de nuevas poéticas productivas en red? Para ilustrar la polémica mercantil y literaria se ha seleccionado un corpus femenino de autoras, puesto que no pueden pasar desapercibidas las oportunidades de visibilización y ruptura de tópicos que ofrece el nuevo canal a la voz poética de la mujer. 
Palabras clave: Poesía femenina contemporánea. Redes sociales. Elvira Sastre. Irene X. Loreto Sesma.

\begin{abstract}
Over the last few years, social networks such as Twitter, Instagram and Youtube have become popular platforms for the publication and diffusion of literary content among young authors to such an extent that many publishing houses have appreciated the opportunity to convert the number of followers into sales. This is revitalizing minority genres such as poetry. One needs to question, though, whether we are seeing a revival of traditional classical poetry or the birth of a new "internet" genre. To illustrate this literary controversy and the resulting business issues, a corpus of female authors has been selected to demonstrate that these new opportunities for exposure, the breaking of stereotypes should not go unnoticed.
\end{abstract}

Key Words: $21^{\text {st }}$ Century Women's Poetry. Social Networks. Elvira Sastre. Irene $\mathrm{X}$. Loreto Sesma.

\title{
1. INTRODUCCIÓN
}

La encendida polémica acerca de este boom de nuevos poetas de la red parece aglutinarse en torno a un paradójico silogismo que podríamos esgrimir así: todo producto poético de calidad tiene un público minoritario, la poesía de las redes sociales arrasa en cifras de ventas, la poesía de las redes sociales no es un producto poético de calidad. Si a esto se añade que el baremo de calidad parte de cánones y canales de comunicación que no pueden ser comparables (tal y como sucede en el caso del correo electrónico y de la carta tradicional), la controversia es aún mayor. Y la valoración 
de la complejidad del fenómeno comunicativo como signo de la nueva realidad digital de la pantalla en la que nos hallamos inmersos, queda así ignorada. Es por ello que resulta fundamental evitar los anacronismos y contextualizar: era digital, generación Y (Millennial) y democratización de la palabra poética. Puesto que conviene no olvidar que la tradición literaria ha dejado constancia de la posición en segundo o incluso tercer plano de la mujer en su acceso a la pluma y que tanto el advenimiento de la democracia como la revolución de las nuevas tecnologías y sus plataformas han sido dos factores clave en el cambio definitivo de tal herencia. ¿Cómo se presentan en sus versos estas poetas nacidas digitales? ¿Qué tratamiento hacen de los temas poéticos habituales? A grandes rasgos, destaca la adopción de una postura activa, desafiante, irreverente así como el reclamo de una palabra literaria femenina articulada sobre un discurso cotidiano-coloquial, que encontrará en el inabarcable e inagotable concepto del amor, su maná poético.

\section{REDES SOCIALES. UNANUEVAMANERADE ESCRIBIR Y PUBLICAR ${ }^{1}$}

Begoña Regueiro Salgado (2013: 237) apuntó acertadamente dos rasgos de poeticidad acaecidos en el siglo XIX que favorecieron la evolución poética posterior que llevaría al nacimiento de la poesía digital actual: por un lado, la no consideración de la poesía o el arte como objetos, sino como procesos, y por otro, la fusión de las artes, traducida a la trasmedialidad actual y encargada de otorgar significados específicos a los distintos códigos. Así se observa en los discursos poéticos de Elvira Sastre, Irene $\mathrm{X}$ y Loreto Sesma, quienes han configurado sus respectivas poéticas teniendo en cuenta las características de contenido, forma y difusión que ofrecen las redes sociales (Twitter, blogs, Youtube...). Elvira Sastre

\footnotetext{
${ }^{1}$ Se utilizarán fragmentos poéticos extraídos de las cuentas de Twitter, blogs y Youtube de las autoras, así como también de las obras publicadas en papel de las mismas (ver referencias bibliográficas finales).
} 
(Segovia, 1992) mantiene viva su actividad literaria en su blog "Relocos y recuerdos" y en su cuenta de Twitter $^{2}$, plataformas que estimularon su fichaje por las editoriales Lapsus Calami (Cuarenta y tres maneras de soltarse el pelo, 2013), Valparaíso (Baluarte, 2014 y Ya nadie baila, 2015) y Visor de Poesía (La soledad de un cuerpo acostumbrado a la herida, 2016); Irene X hace lo propio en @ireneequis ${ }^{3}$, en su blog "Autocrítica. Vomito flores" y en los poemarios consecuentes de su actividad en línea: El sexo de la risa (Harpo, 2015 antes Origami, 2014), Grecia (Harpo, 2015 antes Origami, 2014), No me llores (Harpo, 2015), Fe ciega (Harpo, 2016) y Single (Harpo, 2017); y Loreto Sesma, quien declama su poesía en su canal de Youtube, comparte versos en su cuenta de Twitter ${ }^{4}$ y ocupa escaparates de librerías con 317 kilómetros y dos salidas de emergencia (Espasa, 2014) y Amor revólver (Espasa, 2016).

Sólo analizando las variables mencionadas de contenido, forma y difusión que ofrecen las redes sociales es posible comprender que el fenómeno que examinamos adquiere características y posibilidades diferentes. Ahora bien, ihablar de poesía en blogs y redes sociales es hablar de poesía digital? Dolores Romero López (2011) caracterizaba la poesía publicada a través de estas plataformas bajo la etiqueta de "hiperpoesía", un concepto en el que la crítica establecía "una gradación desde la más simple digitalización del poema a la hipertextualidad y creación de holopoesía, que es la forma más compleja de poesía hipertextual" (2011: 53). Una clasificación muy similar a la establecida por Ana Cuquellera (2011: 70-71) quien utiliza el nombre de "E-vanguardias" para referirse a ciberpoesía de diferente naturaleza: desde poesía analógica alojada en blogs, hasta poesía hipertextual, poesía en movimiento, fotopoesía y videopoesía. Teniendo en cuenta la amplitud del abanico mostrado, los poemas analógicos del blog de Elvira Sastre, los fotopoemas de Irene X o los videopoemas de Loreto Sesma se adscriben al marco que ofrece la

\footnotetext{
2 @elvirasastre, 88,2 k seguidores (última consulta realizada el 2 de enero de 2018).

${ }^{3} 66,1 \mathrm{k}$ seguidores (última consulta realizada el 2 de enero de 2018).

${ }^{4}$ @loretosesma, 70,9 k seguidores (última consulta realizada el 2 de enero de 2018).
} 
nueva textualidad electrónica.

Contenido. La adscripción y el seguimiento del material ofrecido a través de una red social dependerán de las necesidades, intereses o gustos que tengan los cibernautas (Tirira, 2013: 23). Tanto en los textos de Sastre, $\mathrm{X}$ o Sesma como en los de otros poetas de la red se puede leer:

desde el desamor más terrible hasta la historia de amor más envidiable, pasando por las miles de posibilidades que tienen los enfrentamientos cabeza-corazón [...]. Es por el afán de estos autores de acercar sus versos a la realidad que se destapan por completo en cuanto a estilo de vida se refiere (López Megías, 2016: 20).

No es de extrañar por tanto que si los seguidores de estas autoras nacidas en los 90 se corresponden con el grueso adolescente nacido en el 2000, la temática no podía ser más adecuada para enganchar a un público sumido en la mercadotécnica del amor (Rodríguez, 2015) deseoso de empatizar con palabras cercanas a sus vivencias personales. Sucede así que lo público externo y lo privado interno, la realidad y la ficción, parecen borrar e incluso mezclar sus fronteras en el universo de las redes sociales (Millán, 2006: 172) donde la vida personal de las autoras se presenta de manera poetizada. Irene $X$ acompaña imágenes de su vida cotidiana con versos de sus libros (López Megías, 2016: 20) y Elvira Sastre asevera la correspondencia de lo autobiográfico y lo escrito: "Cuando me enamoré por primera vez; fue algo muy platónico y fantasioso. Le quise dar un matiz real y por eso traspasé esa historia al papel, para contarla a mi manera y decirme a mí lo que no le podía decir a ella." (C’Mon Murcia, 2013).

Forma. Viene determinada por la influencia de lo oral-coloquial, por la no persecución consciente de una elaboración del lenguaje y por el recurso a la multimodalidad. Conviene recordar que el nuevo ciberdiscurso juvenil está protagonizado por jóvenes usuarios o prosumidores — consumidor + productor (Sarsa, 2014: 76)- situados “en la cultura de la experimentación, 
la subjetividad y la inmediatez" (Vaqueiro Romero, 2012: 6), rasgos que conducen a la construcción de una conversación más humanizada y con mayor expresividad, atractivo, flexibilidad y carácter lúdico (Berlanga Fernández y Martínez Rodrigo, 2010: 51), en la que ellos mismos admiten que no hay una elaboración del lenguaje "yo no sé lo que es el ritmo, yo no busco nada de eso, yo escribo mis cosas y a la gente le gusta" o "la poesía rimaba y era muy compleja y nosotros hemos inventado un lenguaje nuevo donde podemos decir puta y palabras malsonantes que antes no se podían decir y que llegan mucho más a la gente" (Álvarez, 2017). Sin embargo, pese a tales declaraciones, aún se aprecian ciertos intentos de versificación, metáfora, imagen y sonoridad (Monroy, 2017: s/p) en la construcción de productos multimodales que combinan diversos lenguajes: Elvira Sastre y Loreto Sesma declaman sus poemas con música a través de su canal de Youtube o como enlace hipervínculo a su blog personal, estamos ante una poética que no responde a un único planteamiento ni a una única necesidad y que ni siquiera utiliza en la misma medida las oportunidades que ofrece lo digital (Regueiro Salgado, 2013: 247).

Difusión. Uno de los aspectos más diferenciadores (con respecto al papel) y sobre todo, mejor aprovechados de las plataformas sociales, es su ilimitado poder de distribución y accesibilidad ya que han permitido, entre otros aspectos, abrir la puerta a la democratización de la escritura:

El sistema en su exclusividad comercial no brinda espacios para la difusión, la reflexión y la institucionalización de propuestas complejas o formalmente exigentes. [...] Como respuesta a estos hechos, una creciente cantidad de poetas emergentes opta por el trabajo desde reducidas comunidades lectoras, aceptando esta apuesta como más visible y gratificante que los mecanismos y espacios tradicionales concedidos por la crítica en los medios masivos (Rodríguez Gaona, 2010: 14-15).

La publicación poética deja de ser un privilegio, se viraliza "sin 
jerarquías ni fronteras" (Millán, 2006: 175) a partir de un nuevo escaparate en el que con coste 0 los autores pueden no sólo compartir sus contenidos sino además hacerse amigo del lector tras la pantalla gracias al sistema de retroalimentación de comentarios que ofrecen las distintas plataformas y que subraya el nuevo carácter cuasi bidireccional de la comunicación en red en contraste con el perfil diferido del papel. El autor "en línea" recibe de forma inmediata los me gusta o no me gusta de su público, pudiendo así establecer o no vínculos afectivos con su círculo de lectores, factor que condicionará irremediablemente la autoestima de muchos de ellos. Decenas de seguidoras y seguidores comparten en Twitter mensajes de aplauso, fotografías con las adquisiciones de los libros (Figura 1) de sus ídolos e incluso, improntas en la piel (Figura 2):
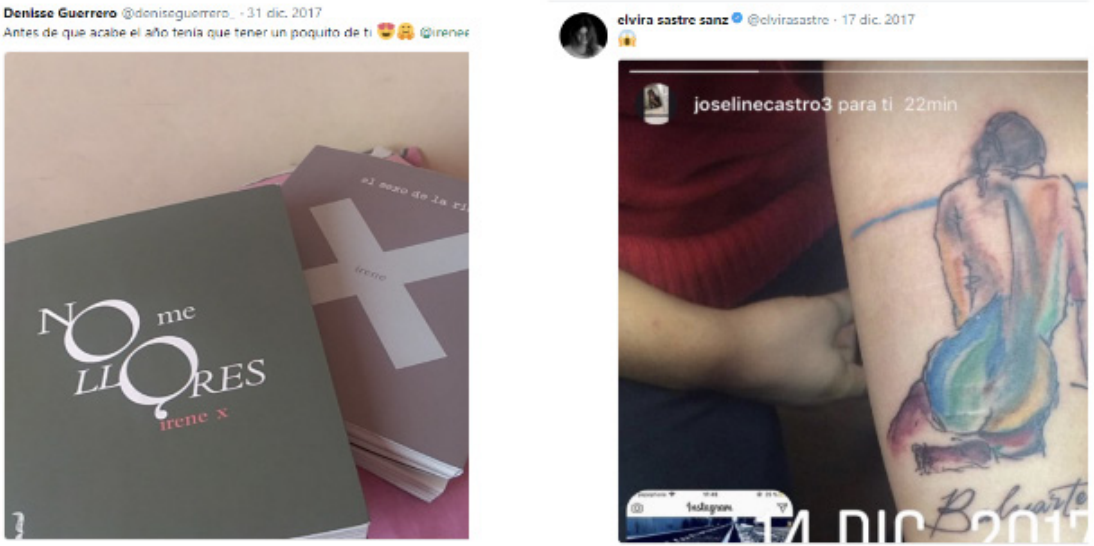

Figura 1. Tuit de una seguidora de Irene $X$ con la portada fotografiada de sus libros.

Figura 2. Tuit de una seguidora de Elvira Sastre con la portada del libro de la autora Baluarte tatuado en el brazo. 
La consecuencia mercantil derivada de este proceso de difusión no tardaría en llegar, materializada — valga la paradoja-por las editoriales del papel. Las empresas del libro muy pronto se apremiarían por convertir los números de seguidores en potenciales compradores de libros, prueba de ello son los datos del informe Comercio interior del libro en España 2015, año en el que la tirada del apartado "Poesía y teatro" cerró con un aumento anual del $26,5 \%$ con respecto del año 2010 , año de la crisis del sector del libro (Velasco, 2017a). Influencia en internet y éxito editorial se convierten por tanto en sinónimos bien avenidos (Monroy, 2017: s/p) primero para las editoriales pequeñas que se atreven a arriesgar por estos autores noveles y después, para las grandes editoriales (como Espasa-Planeta) que una vez visto confirmado el éxito, se los llevan (Vázquez, 2016).

\section{3. ¿REVITALIZACIÓNDELAPOESÍAOCONFIGURACIÓN DE UN NUEVO PRODUCTO LÍRICO?}

Decíamos que la salida al mercado editorial del papel de esta nueva poesía en red es criticada por los garantes del canon clásico debido a su "intrusismo" y a su no cumplimiento con los criterios tradicionalmente asociados a la lírica (Spang, 1993: 58-61). Si el fenómeno hubiera quedado en Twitter o Youtube, muy posiblemente se hubiese visto como una afición tardoadolescente de poetas noveles. Sin embargo, ha dado el salto, incluso cuando ni siquiera las propias poetas tuvieran esa intención, sino simplemente y como reconocen en diversas entrevistas, la de dar rienda suelta a sus emociones "Un día que estaba de exámenes decidí subir un vídeo que ahora me avergüenza mucho (risas), una editorial lo vio y decidió contactar conmigo"s, "Yo vivía en la idea idílica de un blog que era mi habitación y esa habitación a la que dejas entrar a los amigos que todavía no conoces", "Tuvo que decirme alguien que tenía que embarcarme en

\footnotetext{
5"Elvira Sastre: siempre me he sentido a salvo sola", entrevista a Elvira Sastre, El Cultural, 10 de marzo de 2017.

"La poesía da más hambre que de comer", entrevista a Irene X, Acróbata, s/f.
} 
una nueva aventura y que ésta iba a ser ver mis escritos en papel"7.

Intrusismo o no, lo que sí es cierto es que leer sobre papel productos configurados bajo el lenguaje de las redes sociales provoca cierto extrañamiento en el lector acostumbrado al lenguaje de estas redes y no a la poesía de libro, del mismo modo que lo provoca en el lector acostumbrado a la poesía de libro y no al lenguaje de las redes sociales. La adecuación a las nuevas condiciones de comunicación (emisor, receptor, mensaje, canal...) configura los rasgos del discurso del correo electrónico, de servicios de mensajería-chat para teléfono móvil como Whatsapp y de los que podemos advertir en los post de Facebook o los tuit de Twitter. Todos ellos poseen en común una serie de particularidades comunicativas que puso de manifiesto el epistólogo Melançon al hilo de la imposibilidad de comparar la carta tradicional con el email (citado en Vela Delfa, 2007: 175-178). En primer lugar, el carácter inmaterial de los mensajes. La inexistencia del papel como soporte reduce el margen de personalización, convirtiendo estos en productos mucho más estandarizados, que, en el caso de los textos de las redes sociales, al ser publicados en post de forma pública pueden hacerse rápidamente virales y entrar a formar parte del imaginario común de Internet. En segundo lugar, la instantaneidad y la ausencia de espera. Como señalábamos, el margen de respuesta ante una publicación es inmediato, seguidores y detractores pueden mostrar su conformidad o disconformidad ante lo escrito en un lapso de tiempo inmediatamente seguido a la visualización. Los nuevos autores están expuestos de forma permanente a la crítica ajena, contra la que reaccionan (Figura 3):

X @ireneequis.3 dic. 2017

Ayer @KaseO_real llenó el palacio de los deportes con talento, humildad,

lecciones y amor. Sin autotune, egos, insultos, zancadillas o menosprecios. ¿Tengo que explicar algo más?

$Q_{4} \quad$ ᄂ $99 \quad \bigcirc \quad 348$

Figura 3. Tuit de Irene X

\footnotetext{
7"Entrevista a Loreto Sesma, la poeta que arrasa en Youtube", La voz del verso, 20 de diciembre de 2015.
} 
Tercero, y relacionado con el anterior, la brevedad y la rapidez. Los nuevos textos líricos de la red caben en los $140^{8}$ caracteres de Twitter (Figura 4) en los que intentan condensar emoción e ingenio para captar la mirada de los usuarios, en quienes la velocidad de lectura y la falta de tiempo o interés por leer textos más largos se tornan también características, pero no exclusivas, de la nueva comunicación en la red, ya que tanto en los haikus como en los microrrelatos ese mismo deseo de brevedad está presente y son sin embargo, producciones en papel.

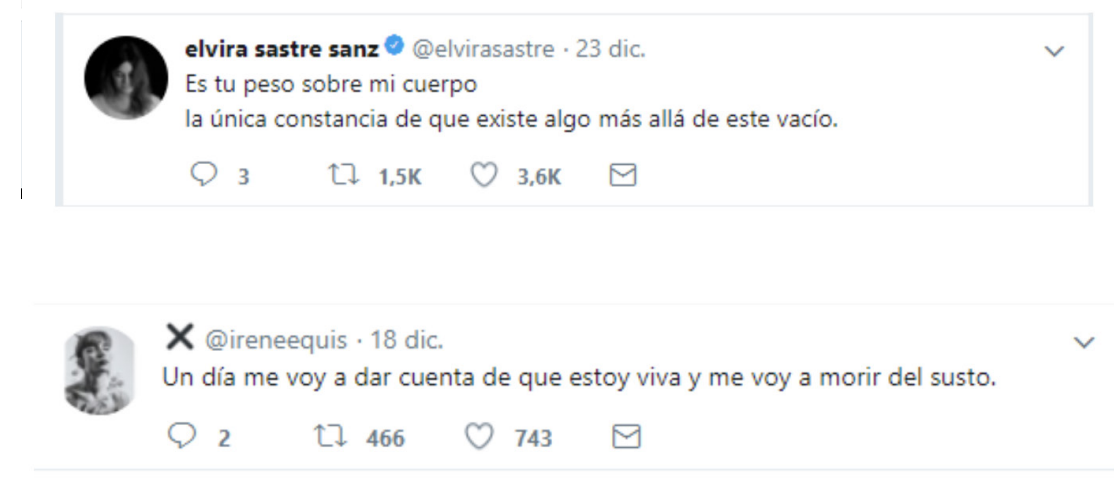

Figura 4. Tuits de Elvira Sastre e Irene X

Y cuarto, las posibilidades multimodales que ofrecen los nuevos mensajes. Se ven, se escuchan, se adelantan, se hace "clic" sobre ellos. El lenguaje poético protagoniza así una gran performance donde "la libertad creativa deja a entrever que estos autores no sólo tienen el don de la palabra, sino que además poseen un gran potencial imaginativo para crear audios de recitados" (López Megías, 2016: 19) (Figura 5).

$\overline{{ }^{8} \text { Ampliados a } 280}$ desde noviembre de 2017. 


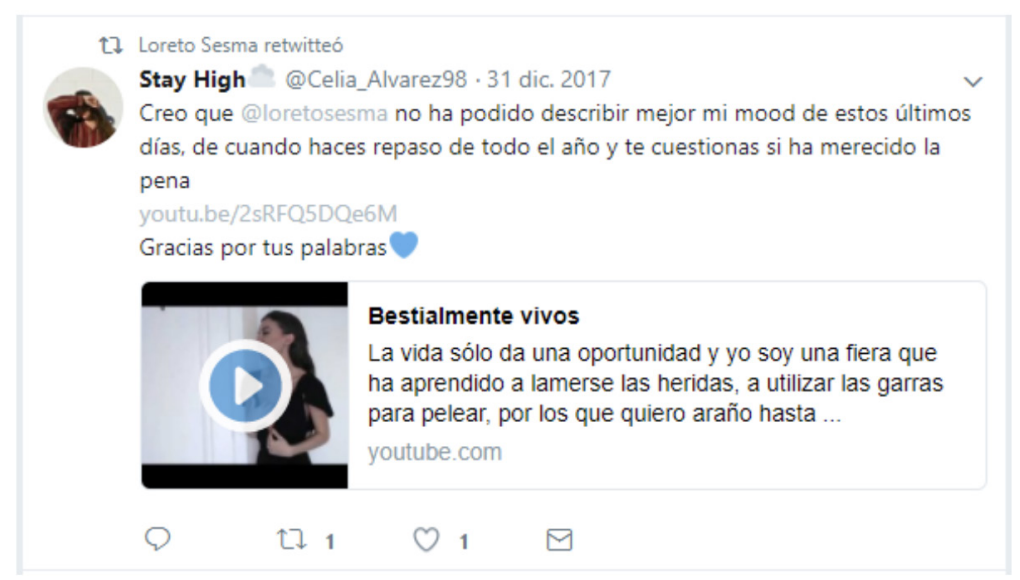

Figura 5. Poema recitado con imágenes de Loreto Sesma subido a su cuenta de Twitter

A estos rasgos habría que añadir la influencia del registro coloquial, de la oralidad, tal y como señalan Berlanga Fernández y Martínez Rodrigo (2010: 57) y que se manifiesta en rasgos como la ya mencionada inmediatez, el dominio de la función emotiva y expresiva, la preeminencia del yo del emisor, la expresión de emociones, sentimientos y estados anímicos como intención comunicativa principal, el predominio de los enunciados exclamativos y desiderativos en modo indicativo y/o subjuntivo a través de la primera persona verbal; el recurso a interjecciones y al lenguaje connotativo, en ocasiones coloquial-vulgar. Si bien es necesario señalar que tal y como ocurría con la mencionada brevedad, estos rasgos no son excluyentes del ámbito digital, puesto que también pueden apreciarse en las publicaciones en papel. Así lo apreciamos en los siguientes poemas de Loreto Sesma e Irene X:

Ojalá el vértigo que supone volar contigo no fuera tan adictivo, este ataque masivo de balas que te has propuesto dispararme acabara de una puta vez 
y me quisieras tanto como yo te quiero.

("Kilómetro", 317 kilómetros y dos salidas de emergencia, p. 27)

Me has visto comportarme como una puta

doler como una enfermedad

follar como mi primera vez

abrazar como la última en llegar

dormir como si tuviese seis vidas

tocarte la nuca como si me quedaran ocho minutos.

(“Aves rapaces”, El sexo de la risa, p. 115)

Si bien, visto lo visto, no nos encontramos ante una poesía del canon clásico del papel, intencionalidad negada incluso por sus propias autoras: "Yo no escribo poemas" (Irene X citada en Monroy, 2017: s/p) o "Pero, / aun así / me gusta contar que una vez conocí el amor y que por eso / escribo poesía. / Aunque aquello no fuera amor, / ni esto sea poesía." (Sesma, 2016: 17) sí que podemos apreciar en estos productos poéticos en red ciertos rasgos coincidentes con lo que Kurt Spang (1993: 58-61) señaló como premisas propias de lo lírico: interiorización anímica y brevedad e intensidad; ausencia de historia y predilección por la instantánea; predominio de la función poética del lenguaje, si bien a este respecto podemos señalar cómo la función poética se centra más bien en lo léxico-semántico que en lo fonético-fonológico, tal y como señala Velasco (2017a) aludiendo a un acceso no habitual metafórico del lenguaje basado en el "uso de imágenes pseudoingeniosas (construidas a partir de un léxico estereotipado y cotidiano) que sirven para poner en juego deseos o emociones superlativos y que funcionan de manera similar a la vieja idea de lo metafórico" y donde podemos encontrar recursos retóricos clásicos, siendo metáforas ("Hay mujeres / que son estaciones de (d)año, / tormentas torrenciales en agosto y estufa / en un diciembre lleno de abandonos", Elvira Sastre, Ya nadie baila, p. 88), hipérboles ("y me dedicas una sonrisa 
/ de esas que hacen el mundo zumo de naranja", Irene X, El sexo de la risa, p. 32), símiles ("Y yo me sentía como un cubo de rubik / en manos de un daltónico. / Como si fuera el grito de un afónico cuando está ahogándose a / la deriva / y un barco lo esquiva", Loreto Sesma, Amor revólver, p. 85), anáforas (Figura 6), juegos de palabras (“¿Quién me tiende / y quien me tiene? / ¿Quién me entiende?”, Elvira Sastre, Ya nadie Baila, p. 61) y guiños intertextuales (Figura 7) los más habituales.

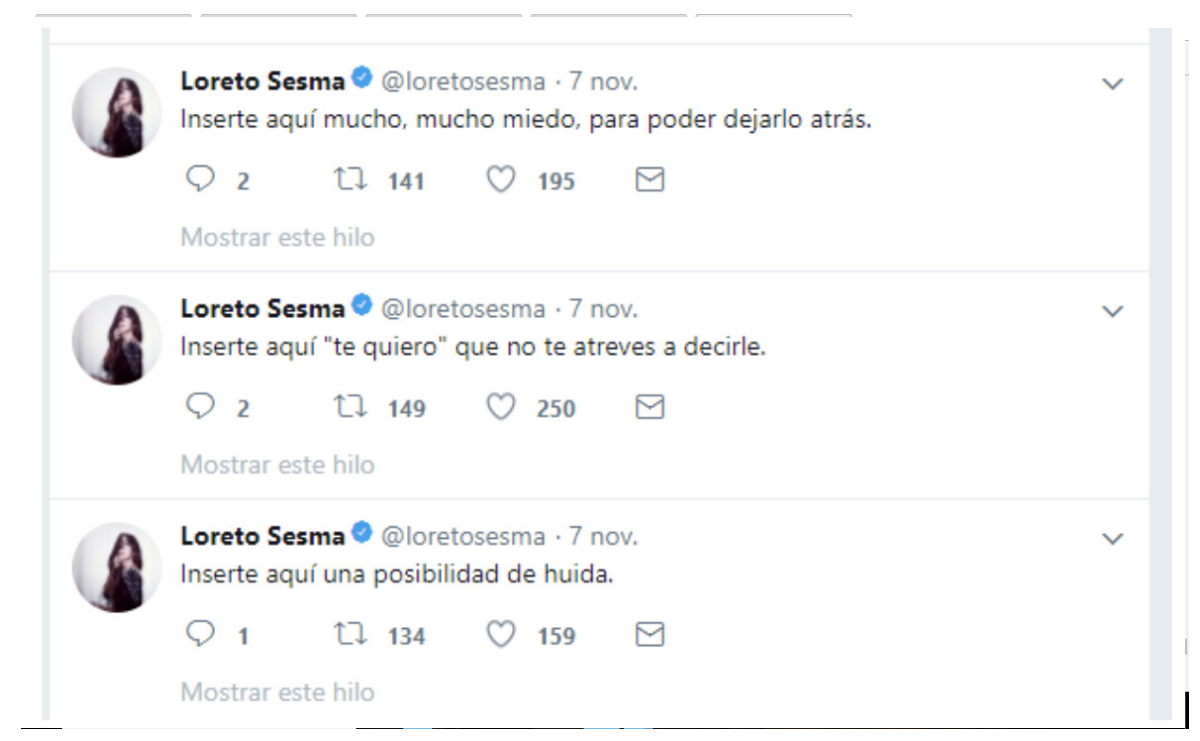

Figura 6. Tuits de Loreto Sesma

\section{$\mathbf{X} @$ ireneequis·21 nov.}

Y siempre también es todavía. \#nomellores instagram.com/p/BbwXJHHjzka/

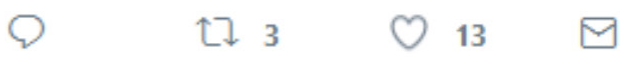

Figura 7. Tuit de Irene $X$ 
En cuanto a la disposición, cabe destacar la forma "atectónica" (Spang, 1993: 60), ya que las nuevas composiciones no se ajustan a esquemas preestablecidos sino a la voluntad expresiva del autor, aspecto en el que los procedimientos tipográficos adquieren gran importancia, dada la fuerza que va adquiriendo progresivamente lo visual (Figura 8).

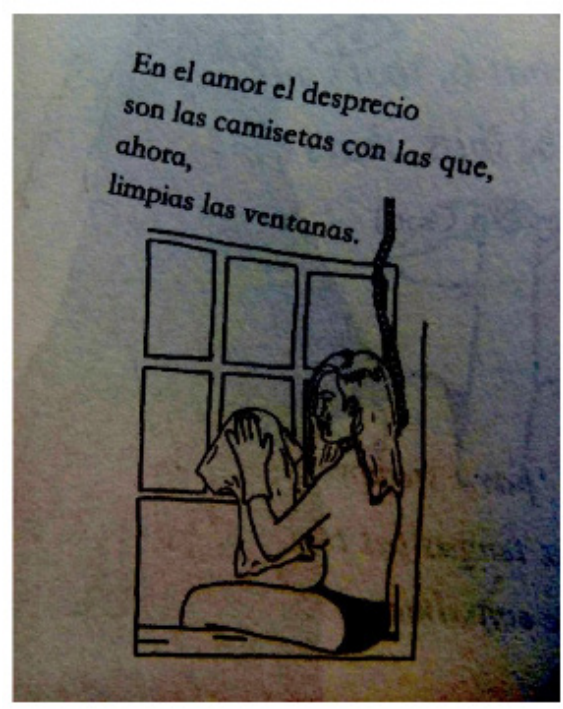

Figura 8. Poema de Irene X (Fe ciega, p. 18)

Podemos señalar que la musicalidad y el ritmo son los aspectos de los que más adolecen estas nuevas formas líricas, ya que en su mayoría constituyen una adopción del lenguaje en su cotidianeidad sin una voluntad en la configuración melódica de tónicas y átonas. Confirmamos así lo dispuesto por Monroy (2017: s/p) cuando afirma que:

la aparición de Internet no significa una ruptura significativa con el lirismo y los tópicos (la adolescencia sigue siendo nada más que adolescencia), sí marca un antes y un después en nuestra relación con muchas de las estructuras propias del lenguaje poético. Precisamente de este cambio en la posición 
del lenguaje, surge la posibilidad de que su uso cotidiano en las redes sociales se confunda con una forma de producción poética. Esta hermosa confusión no debería asustarnos. Debería ayudarnos — si somos lo bastante buenos - a superar una vieja idea, heredada e insostenible, de lo que es la poesía.

Y así, de hecho, aunque quizá se pueda entrever algún mínimo hilo de conexión con la poesía tradicional que ejerce como principal antecedente, la poesía de la experiencia, al menos en la búsqueda de una expresión comprensible, alejada del oscurantismo (Velasco, 2017b), lo interesante no es la conexión con el pasado, sino la construcción de un modo nuevo, en un contexto diferente que nos invite a reflexionar sobre la configuración del nuevo lenguaje de las pantallas y sus características y en ese mundo de transparencia y visibilidad en el que la propia vida se vuelve producto, el cuestionamiento sobre si nos encontramos ante el agotamiento de la imaginación o el desplazamiento de la ficción (Jaume, 2017).

\section{ELLAS TOMAN EL TUIT}

María Rosal Nadales realizó un cuestionario a 26 mujeres poetas jóvenes actuales que alternan la publicación en papel con la publicación en red y que fueron seleccionadas partiendo de la antología Generación 2001. 26 poetas españolas (sin peaje), publicada por la revista La Manzana Poética (2014). Todas ellas contaban con fechas de nacimiento posteriores a 1975 y disponían en su haber de, al menos, dos libros publicados. De dicho cuestionario, la autora obtuvo como respuesta unánime la confirmación de que la democratización de Internet había permitido una difusión igualitaria para ambos géneros (Rosal Nadales, 2016: 202). Así, las poéticas de Elvira Sastre, Irene X y Loreto Sesma encuentran las mismas (o ninguna) trabas a la hora de divulgar sus contenidos poéticos tal y como hacen Escandar Algeet, Marcus Versus o Defreds, sus compañeros de gremio. Dicha "barra 
libre" de acceso no puede ser ignorada, sobre todo si tenemos en cuenta la carrera de fondo que ha llevado (y que sigue llevando) a cabo la producción literaria femenina por abrirse camino y visibilidad desde los años 80 (Rosal Nadales, 2006: 403), tal y como han probado desde entonces las numerosas iniciativas y antologías desarrolladas para "contrarrestar las prolongadas ausencias" (Keefe Ugalde, 2007: 9) y que, en la actualidad, si tenemos en cuenta algunos datos referentes a nóminas de autoras en ciertas editoriales poeticas actuales ${ }^{9}$, todavía queda camino por recorrer.

Además de sumar visibilidad numérica, la recuperación del protagonismo poético femenino ha venido acompañada de una serie de rasgos que ponen de manifiesto la adecuación del contenido y de la forma a las directrices socioculturales feministas del siglo XXI, tales como el abandono del rol pasivo - "la mujer ya no es el reposo del guerrero, no admira al varón como un héroe en un pedestal ni lo espera" (Rosal Nadales, 2006: 680)— y la superación del amor romántico entendido como una “especie de cautiverio" (Keefe Ugalde, 2007: 12):

\section{Entonces,}

no sé cómo,

me sentí ave fénix.

Le miré a los ojos,

miré cómo se relamía las manos que tanto me habían acariciado

y se iba a revolcarse a otros barros.

$Y$ así le vi irse en dirección contraria a mí, con una manzana en la boca, andando con una elegancia digna de un cinco jotas,

${ }^{9}$ La Editorial Frida (hoy bajo el nombre de Muevetulengua) alberga en su nómina de poetas jóvenes a 28 hombres y a 9 mujeres, de acuerdo con los datos extraídos de su propia página web. 
mi amor,

tanto pasearte en otras bocas

y ahora me toca a mi disfrutar del festín.

¿O acaso no sabías que a todo cerdo le llega su San Martín?

(Loreto Sesma, “12”, Amor revólver, p. 38)

\begin{abstract}
Asimismo, está la reivindicación del cuerpo y de la sexualidad femenina, donde es posible celebrar sin atrevimiento y recuperar los placeres de las mujeres (Keefe Ugalde, 2007: 61):
\end{abstract}

Y es que resulta que a mí el crimen

me pilló masturbándote,

amor,

o masturbándome pensando en ti.

Como si hubiera diferencia.

Como si no fuera lo mismo

amarte, amarme y amarnos.

(Elvira Sastre, "Eres lo más bonito que he hecho por mí", Baluarte, p. 38)

No me gustó que le comieses

el coño a mi mejor amiga en la cama donde te lo comía yo, pero lo que menos me gustó fue darme cuenta de que la quería más a ella que a ti.

(Irene X, "No me gustó", Fe ciega, p. 71)

Por último, puede destacarse la denuncia de la violencia de género: 
En el amor el respeto

es insultarte bajio,

a gritos,

a carcajadas,

a lametones

y a mordiscos.

Sabiendo que las palabras portan el significado

que uno les entregue.

Y también guardarlo y

también que lo sepan.

En el amor el respeto

también es que sepan que lo guardas.

En el amor la tranquilidad

es apoyar la cabeza en el latido

que confirma que estoy viva.

En el amor la humillación

NO es amor.

En el amor la humillación

no cabe,

no entra,

hasta aquí podia llegar

(Irene X, "En el amor", Fe ciega, p. 32)

Para todos estos aspectos, se recurre, como vemos, a un lenguaje coloquial-conversacional y sin tapujos, en un diálogo público-privado del yo-tú yuxtapuesto o coordinado. Todo ello, ambientado en un paisaje urbano (Rosal Nadales, 2006: 651) en el que sobresalen con frecuencia las 
calles de Madrid ${ }^{10}$ :

me acuerdo

del billete de metro de aquel viernes que nos fuimos de cervezas

[por

Malasaña,

de que tengo guardados algunos trozos de la pantalla rota de tu

[móvil,

(Loreto Sesma, "Kilómetro", 317 kilómetros y dos salidas de emergencia, p. 27)

$Y$ de repente pasa,

sin esperarte ha pasado.

No te has ido y ya te echo de menos,

te acabo de besar

y mi saliva se multiplica queriendo más,

cruzas la puerta

y ya me relamo los dedos para guardarte,

paseo por Madrid

y te quiero conmigo en cada esquina.

(Elvira Sastre, "Quiero hacer contigo todo lo que la poesía aún no ha escrito", Ya nadie baila, p. 26)

$Y$ en tus manos de cobre encontré la electricidad con la que un dia

fundimos todas las farolas de Gran Vía a ganas....

\footnotetext{
${ }^{10}$ Elvira Sastre e Irene X residen en la ciudad y Loreto Sesma considera Madrid como su "ciudad de emergencia", según una entrevista realizada por Ana Salas a la poeta para la versión digital de Vanity Fair el 15 de octubre de 2017.
} 
(Irene X, “margaritas", El sexo de la risa, p. 209)

\section{CONCLUSIÓN}

Podemos concluir indicando que hablar de las poéticas de Elvira Sastre, Irene X y Loreto Sesma es referirse a una productiva poética lírica emergida de la realidad comunicativa imperante de las redes sociales, que si bien puede mantener algún ligero hilo de continuidad para con el pasado (rechazo al oscurantismo, uso de figuras retóricas clásicas), su contexto se "versa" en presente y en futuro. La publicación en papel de la obra de las autoras no debe distraer ni condenar la consideración de estas nuevas poéticas en red, sino quedar reducida su crítica a la estrategia mercantil de las editoriales, ya que si no, se induce al error de querer comparar anacrónicamente lo nuevo desde los parámetros de la tradicional. Lo interesante es el nuevo planteamiento de esa literatura digital que "se escribe y compone para ser leída en Internet principalmente” (Romero López, 2011: 38) en un variado abanico de posibilidades, unas veces más cercana a la disposición del poema analógico en un entorno web, otras sumergiéndose en la utilización plena de recursos multimedia (imagen en movimiento, música, efectos) propios de las plataformas digitales.

Asimismo, la estimulación creativa de la palabra poética a través de las redes sociales ha conseguido interesar a los adolescentes y despertar su expresión y debate sin tapujos sobre temas como el cuerpo, el sexo o la denuncia de realidades sociales como la violencia de género. El contagio de estas poéticas en la proliferación de cuentas Twitter, blogs y canales de Youtube ha contribuido a favorecer la conectividad de jóvenes poetas y aficionados a la poesía que intercambian comentarios, referencias y comparten un nuevo canon de autores y de autoras actuales. No obstante, aún llevará tiempo y espera observar si se trata de la inventiva de una sentimentalidad y estética lírica oportunista y pasajera que será superada por "los poetas jóvenes que no salen en las listas, los que no salen en 
YouTube, los otros, los ocultos, los pacientes, los rechazados" (Álvarez, 2017) o si nos encontramos verdaderamente en la génesis del gran cambio hacia la escritura literaria 2.0.

\section{REFERENCIAS BIBLIOGRÁFICAS}

ÁLVAREZ, D. (2017). "Tras el boom de los nuevos poetas, llega la poesía”. Ocultalit. Disponible en línea: http://www.ocultalit.com/opinion/ poesia-nuevos-poetas/ [03/03/2018].

BERLANGA FERNÁNDEZ, I. y MARTÍNEZ RODRIGO, E. (2010). "Ciberlenguaje y principios de retórica clásica. Redes sociales: el caso Facebook”. Enl@ace: Revista Venezolana de Información, Tecnología y Conocimiento 7.2, 47-61.

C'MON MURCIA, S. (2013). "Entrevista a Elvira Sastre”. Disponible en línea: http://cmonmurcia.com/entrevista-a-elvira-sastre/ [05/01/2018].

CEDILLO, J. (2017). "Elvira Sastre: siempre me he sentido a salvo sola". El Cultural. Disponible en línea: http://acrobata.es/entrevistairene- $x /$ [06/01/2018].

CID RODRÍGUEZ, G. (s/f). "La poesía da más hambre que de comer". Acróbata. Disponible en línea: http://www.elcultural.com/ noticias/letras/Elvira-Sastre-Siempre-me-he-sentido-a-salvo-solal [01/01/2018].

CUQUELLERA, A. (2011). "E-tertulias, E-vanguardias, E-juglaria. La poesía que se aloja en las bitácoras españolas. Algunos ejemplos de remediación del canon poético en estos blogs". Revista Texto digital 7.1, 67-93.

JAUME, A. (2017). "El malentendido de la experiencia". Ctxt 112. Disponible en línea: http://ctxt.es/es/20170412/Culturas/12148/ poesia-juvenil-Andreu-Jaume-Unai-Velasco.htm [27/12/2017]. 
KEEFE UGALDE, S. (2007). En voz alta. Las poetas de las generaciones de los 50 y los 70. Madrid: Hiperión.

(1991). Conversaciones y poemas. La nueva poesía femenina española en castellano. Madrid: Siglo XXI.

LA VOZ DEL VERSO (2015). "Entrevista a Loreto Sesma, la poeta que arrasa en Youtube". Disponible en línea: http://www.lavozdelverso. com/entrevista-a-loreto-sesma-la-poeta-que-arrasa-en-Youtubel [02/01/2018]

LÓPEZ MEGÍAS, E. (2016). Literatura en Internet: poesía en redes sociales. Universidad de Valladolid (también en http://uvadoc.uva. es/bitstream/10324/18139/1/TFG-N.463.pdf [02/01/2018]).

MILLÁN, T. (2006). "La digitalización de la realidad en las nuevas generaciones del siglo XXI". Comunicar 26, 171-175.

MONROY, V. (2017). "Yo no escribo poemas". CTXT 106, s/p. Disponible en línea: http://ctxt.es/es/20170301/Culturas/11426/poesia-redessociales-vicente-monroy-irene-x.htm [06/01/2018].

MUEVE TU LENGUA EDICIONES. (2018). “Autores". Disponible en línea: https://www.muevetulengua.com/content/7-autores [03/03/18].

REGUEIRO SALGADO, B. (2011). "Entre la obra total y el juego: neorromanticismo y vanguardismo en la poesía digital escrita en español. Un ensayo de clasificación". Revista Texto Digital 7.1, 94121.

(2013). “Qué es poesía?: la literariedad en la poesía digital”. En XVIII Simposio de la SELGYC (Alicante 9-11 de septiembre 2010) = XVIII Simposi de la SELGYC (Alacant 9-11 setembre de 2010). Ciberliteratura i comparatisme $=$ Ciberliteratura y comparatismo, 233-248. Alacant: Universitat d'Alacant / SELGYC [Sociedad Española de Literatura General y Comparada].

RODRÍGUEZ, N. (2015). El nuevo ideal del amor en adolescentes digitales. Bilbao: Desclee De Brouwer.

RODRÍGUEZ-GAONA, M. (2010). Mejorando lo presente. Poesía 
española última: Posmodernidad, Humanismo y Redes. Madrid: Caballo de Troya.

ROMERO LÓPEZ, D. (2011). "La literatura digital en español: estado de la cuestión”. Revista Texto digital 7.1, 38-66.

ROSALNADALES, M.(2006).Poesía y poética en las escritoras españolas actuales 1970-2005. Tesis Doctoral: Universidad de Granada. Disponible en línea: https://hera.ugr.es/tesisugr/16151446.pdf [11/04/2018].

(2016). "La poesía en los tiempos del blog: jóvenes poetas españolas". Sociocriticism 31.1, 181-207.

SARSA, J (2014). "El perfil prosumidor de los estudiantes en la web 2.0". Journal for Educators, Teachers and Trainers 5.2, 74-87.

SASTRE, E. (2014). Baluarte. Granada: Valparaíso Ediciones. (2015). Ya nadie baila. Granada: Valparaíso Ediciones. (2016). La soledad de un cuerpo acostumbrado a la herida. Madrid: Visor.

(s/f). http://bleuparapluie.blogspot.com.es/ [03/01/2018]. (s/f). https://Twitter.com/elvirasastre [03/01/2018].

SESMA, L. (2014). 317 kilómetros y dos salidas de emergencia. Madrid: Espasa. (2016). Amor revólver. Madrid: Espasa. (s/f) https://www.youtube.com/user/loretosesma [05/01/2018]. (s/f) https://Twitter.com/loretosesma [05/01/2018].

SPANG, K. (1993). Géneros literarios. Madrid: Síntesis.

TIRIRA, M. (2013). "La escritura en las redes sociales". Revista para el aula 8 (Universidad San Francisco de Quito), 22-23.

VAQUEIRO ROMERO, M. (2012). "Ciberlenguaje juvenil en las redes sociales". Congreso Iberoamericano de las Lenguas en la Educación y en la Cultura/IV Congreso Leer.es, Salamanca, 5-7 septiembre.

VÁZQUEZ, C. H. (2016). “¿Sobran poetas?”, Ctxt, 97. Disponible en línea: http://ctxt.es/es/20161228/Culturas/10277/reportaje-poesia- 
jam-sessions-aleatorio-editoriales-quiebra-nuevas-poetas.htm [03/01/2018].

VELA DELFA, C. (2007). El correo electrónico: el nacimiento de un nuevo género. Universidad Complutense de Madrid. En http:// eprints.ucm.es/7400/ [03/01/2018].

(2012). "Una aproximación del correo electrónico desde una perspectiva diacrónica: evolución y asentamiento de un género discursivo". Cuadernos de Linguagem e Sociedades 17.2, 55-78.

VELASCO, U. (2017a). "50 kilos de adolescencia, 200 gramos de Internet", Ctxt, 99. Disponible en línea: http://ctxt.es/es/20170111/ Culturas/10522/nueva-poesia-jovenes-poetas-Internet-redessociales-fenómeno-comercial.htm [27/12/2017].

(2017b). "50 kilos de adolescencia, 200 gramos de Internet II", Ctxt, 100. Disponible en línea: http://ctxt.es/es/20170118/ Culturas/10723/boom-jovenes-poetas-elvira-sastre-poesia-de-laexperiencia.htm [27/12/2017].

X, I. (2014). El sexo de la risa. Madrid: Harpo. (2016). Fe ciega. Madrid: Harpo. (2017). Single. Madrid: Harpo. (s/f). http://mellamoirene.blogspot.com.es/ [05/01/2018]. (s/f). https://Twitter.com/ireneequis [05/01/2018].

Recibido el 10 de enero de 2018 Aceptado el 11 de abril de 2018 